\title{
Evaluation of Neurological Complications in Hospitalized COVID-19 Patients: A Cross-Sectional Study 2020
}

\section{Mojtaba Khazaei}

Hamedan University of Medical Sciences

Fatemeh Feizy ( $\square$ Feizy_fatemeh@yahoo.com )

Hamedan University of Medical Sciences

Salman Khazaei

Hamedan University of Medical Sciences

\section{Research Article}

Keywords: COVID-19, Neurologic complications, hospitalized patients

Posted Date: April 8th, 2021

DOI: https://doi.org/10.21203/rs.3.rs-360768/v1

License: (c) (i) This work is licensed under a Creative Commons Attribution 4.0 International License.

Read Full License 


\section{Abstract}

Objective: The coronavirus (COVID-19) has been spreading around the world since December 2019. Neurological symptoms have been reported as a part of the clinical spectrum of the disease. This study aimed to determine the frequency of neurological complications in hospitalized patients with COVID- 19 .

Methods: Electronic medical records in the hospital information system, laboratory findings, and radiological examinations were evaluated for all patients with laboratory-confirmed SARS-CoV-2 infection. The cases were referred to Shahid Beheshti Hospital affiliated to Hamadan University of Medical Sciences from February 20, 2020 to the end of the same year.

Results: A total of 477 hospitalized COVID-19 patients were included in the analyses. Based on our results, 105 (22.02\%) patients showed neurological manifestations. Ischemic stroke, decreased consciousness, and headache were the most frequent reported neurological symptoms with the rate of 34 (7.13\%), 28 (5.88\%), and13 (2.72\%), respectively. Moreover, 54 (51.43\%) cases were male, and the vast majority of the patients $(66 ; 62.86 \%)$ had more than 60 years of age.

Conclusions: SARS-CoV-2 may involve nervous system and cause brain tissue damage. The findings of this study provide more information on coronavirus disease, contributing to effective interventions for the control of the disease

\section{Introduction}

In December 2019, people in China began falling ill with an unknown virus, which the World Health Organization (WHO) announced the outbreak of COVID-19. The disease was first appeared in Wuhan and then spread rapidly to other cities of China and Asian countries, as well as to Europe and North America[1]. COVID-19 is caused by infection with severe acute respiratory syndrome coronavirus 2 (SARCCoV-2) originated from animals and animal host; therefore, there is definitely a contaminated animal source for the infection[2].

In the late December of 2019, the number of COVID-19 cases was increasingly raising. As of August 1 , 2020, the number of COVID-19 patients identified worldwide was 17,902,949, among which 685802 cases were died, accounting for the mortality rate of $6 \%$. However, among 306,752 cases identified in Iran to date, virtually 16,982 cases have led to death. National and global statistics of coronavirus pandemic have revealed a very high percentage of COVID-19 patients with a critical situation in Iran, which is due to the specific sampling of critically ill and hospitalized cases in the country[3].

Many investigations have been conducted to evaluate the clinical aspects of the COVID-19 disease, and the results have indicated that the patients have modified the degree of clinical symptoms, from mild fever or cough to pneumonia and extensive involvement of various organ functions with a mortality rate of $2 \%$ to $4 \%$. In addition, an increasing number of COVID-19 patients has been reported with the sudden loss of smell and taste[4]. According to some recent reports, besides systemic and respiratory symptoms, 
$36.4 \%$ of the patients has shown neurological signs, including headache, parasthesia, impaired consciousness, and encephalitis. Moreover, patients with severe forms of the disease have displayed more neurological symptoms than those with mild to moderate disease[5]. Autopsy reports have suggested brain tissue edema and partial nerve degeneration in deceased patients[6].

COVID-19 infection has been widely reported as a cause of cytokine storm syndrome, probably one of the factors causing acute brain disease[7]. Patients with COVID-19 infection and nervous manifestations ften show the high levels of D-dimer and severe platelet depletion, which may expose these patients to acute cerebrovascular events[8]. By genome sequencing, researchers have verified the presence of SARS-CoV-2 in cerebrospinal fluid (CSF), reflecting that COVID-19 infection has the potential to damage the nervous system[9]. Owing to the COVID-19 epidemic and rapid transmission, physicians need to be aware of the effects of this disease on various body organs, particularly the brain. Considering the above-mentioned evidence, this study was designed to assess the incidence of neurological disorders in patients with COVID-19.

\section{Materials And Methods}

The present registry-based observational study was conducted on 477 hospitalized COVID-19 cases referred to Shahid Beheshti Hospital affiliated to Hamadan University of Medical Sciences from February 20,2020 to the end of 2020. This hospital was designated by the government to treat patients with neurological disorders during the course of COVID-19. Diagnosis of the disease was performed based on the results of real-time reverse-transcriptase polymerase chain reaction (RT-PCR) of nasopharyngeal and oropharyngeal (NP/OP) swabs. Radiologic assessments included chest and head computed tomography (CT), laboratory testing (such as plt, white blood cell count), which was carried out with regard to the clinical care needs of each patient.

\section{Data collection}

We reviewed electronic medical records in the hospital information system, laboratory findings, and radiologic examinations (head and chest $\mathrm{CT}$ ) for all patients with laboratory-confirmed SARS-CoV-2 infection. Demographic information collected comprises of gender, age, education level, and history of smoking and comorbidities (hypertension, diabetes, cardiac or cerebrovascular, and other underlying diseases). Therefore, accurate history of the patients was obtained by an assistant neurologist, and the subjective and objective data were recorded. Neurological manifestations were reviewed and confirmed by a neurologist and classified into two categories: central nervous system (CNS) and peripheral nervous system (PNS) manifestations.

\section{Classification of CNS disorder}

Acute cerebrovascular diseases, ischemic stroke, and intracerebral hemorrhage are acute vascular lesions that occur in the blood vessels of the brain and can be diagnosed by clinical symptoms and head CT or resonance imaging (MRI)[10]. Seizures cause an unpleasant sensation and stimulation of brain cells that 
may be reflected in the whole or part of the body, which is based on the clinical symptoms at the time of presentation[11]. Multiple sclerosis (MS) is an autoimmune chronic inflammatory demyelinating disease of CNS detectable by MRI and clinical signs[12,13]. Encephalitis is a serious inflammation and the swelling of the brain. The etiology of the disease is viral, though it is difficult to identify the main cause. Often, it is diagnosed by CT, MRI, and clinical and laboratory methods[14].

\section{Classification of PNS disorder}

Guillain-Barre syndrome (GBS) is an autoimmune and acute polyneuropathy disorder related to the PNS. The clinical characteristics of GBS are variable degree of limb weakness and decline in or loss of tendon reflexes[15]. Anosmia is known as the complete loss of smell sensation[16]. Polyneuropathy is primarily a distal axonopathy in which distal degeneration of both motor and sensory axons, without inflammation, occurs. The underlying cause of the axonal degeneration may relate to the lack of vascular autoregulation and increased microvascular permeability, resulting in endoneurial edema and capillary occlusion[17,18]. Myopathy, a disease of muscle, is the loss of myosin filaments[19]. Other neurologic manifestations that did not meet any of these criteria were categorized as others.

\section{Statistical analysis}

Descriptive statistics were reported as number for categorical variables and mean (SD) for continuous variables across the patient's background. The relationship between neurological symptoms in the patients (gender and age groups) was assessed by chi-squared and exact fisher's tests. All the statistical analyses were conducted in STATA version 14 software. Significant level of less than $5 \%$ was considered as statistically significant.

\section{Ethics}

The protocol of the study was approved by the Ethics Committee of Hamadan University of Medical Sciences (ethical code: IR.UMSHA.REC.1399.511). All participants received oral and written information about the purpose of the study. It became clear to them that their participation was voluntary and that the data remained confidential.

\section{Results}

A total of 477 hospitalized COVID-19 patients were included in the analyses. Their demographic characteristics based on the occurrence of CNS symptoms are shown in Table HYPERLINK "https://jamanetwork.com/journals/jamaneurology/fullarticle/2764549"1. The number of patients with neurological manifestations was $105(22.02 \%)$. Among the patients, $54(51.43 \%)$ were males, and 66 $(62.86 \%)$ had more than 60 years of age. Only $16(3.35 \%)$ cases were unmarried, and the rest was married. Besides, 52 (11.32\%) cases were smoker. The patients with CNS, compared to those without CNS symptoms, were homogenous regarding gender, age group, and marital status $(P>0.05)$. However, the proportion of CNS symptoms were significantly higher in smokers than non-smokers (21.9\% vs. $8.33 \%$; 
$P<0.001)$. In both groups of patients with and without neurological symptoms, no significant difference was observed ( $(P=0.66)$. The rate of COVID-19-related death was significantly higher in patients with than without neurological symptoms (30.47\% vs. $19.62 \%, \mathrm{P}=0.012)$.

In Table 2, we compared the occurrence of neurological symptoms based on the patients' gender. Overall, ischemic stroke (7.13\%), decreased consciousness (5.88\%), and convulsion (2.31\%) were the most common reported neurological symptoms. However, encephalitis, ischemic stroke, venous thrombosis, and hyposmia were more observed in females, and others were more found in males $(P>0.05)$. The occurrence of neurological symptoms based on the age groups of patients is presented in Table 3 . As it is apparent from the Table, these symptoms are uncommon among cases below 30 years of age, and the greater neurological symptoms are associated with the patients over 60 years.

In Table 4, Laboratory results showed that the platelet count in patients with neurological manifestation was in the normal range and in WBC count the lymphocyte was below the normal range and neutrophile was slightly above the normal range.

\section{Discussion}

This study shows the prevalence of neurological manifestations in 105 (22.02\%) hospitalized patients with COVID-19. CNS failure was the main form of neurological symptoms in these patients. Neurological manifestations of patients with COVID-19 have been reported to be $36.4 \%$ in China and $57.4 \%$ in Europe[20,21]. CT findings of the brain of most COVID-19 patients, particularly those with severe respiratory failure, have indicated cerebral hemisphere infarction or matter abnormalities and acute cerebrovascular disease, including intracranial hemorrhage, large-vessel occlusion, and acute or subacute ischemic stroke. In our study, cerebrovascular disease and impaired consciousness were predominantly the most common neurological manifestations observed in the patients who were referred to the hospital as an emergency case with decreased level of consciousness and often with unusual symptoms of COVID-19, including fever and cough. Their pulmonary lesions were found by immediate lung CT. Besides, using a positive RT-PCR detection, the patients were diagnosed as having COVID-19. Laboratory findings have also demonstrated that the mean lymphocyte level in patients was slightly lower, and neutrophils were higher than normal, suggestive of an immune response, especially $T$ cells, to the virus. Similarly, American Thoracic Society guidelines for community-acquired pneumonia has reported that nervous system disorders are significantly more frequent in severe than non-severe infections ( $45.5 \%$ vs. $30.2 \%)$. The highest frequency of neurological manifestations was detected in COVID-19 patients with severe respiratory failure disease, acute cerebrovascular disease (5.7\%), impaired consciousness (14.8\%), and skeletal muscle injury (19.3\%). Cerebrovascular disease and impaired consciousness were acute and asymptomatic in the early stages of the disease (median time: 1-2 days). Based on laboratory findings, patients with severe compared to no-severe respiratory infection displayed higher inflammatory responses, including high white blood cells and neutrophil counts, lower lymphocyte counts, and increased levels of C-reactive protein compared to patients[22]. In the present study, ischemic stroke, decreased consciousness, and headache were the most frequent reported neurological symptoms, with 
the rates of $34(7.13 \%), 28(5.88 \%)$, and $13(2.72 \%)$, respectively. However, GBS and encephalitis, with the rates of $2(0.42 \%)$ and $5(1.05 \%)$, respectively, were uncommon. In a number of former investigations, acute ischemic strokes occurred in 31\% of 108 COVID-19 hospitalized patients, and 3 out of 15 patients with neurological manifestations had stroke and GBS the least.[23-25]. In an observational study of 219 COVID-19 patients with cerebrovascular disease, $10(4.6 \%)$ patients had acute ischemic stroke, and only one $(0.5 \%)$ suffered from cerebral hemorrhage[26]. However, in another investigation on 214 COVID-19 patients in Wuhan of China, headaches (17\%) and dizziness (13\%) were the highest CNS symptoms, but cerebrovascular $(0.3 \%)$ and seizures $(0.5 \%)$ were the lowest[20]. These results were slightly different from those of our study. In a study of neurological symptoms in patients with COVID-19, the most common neurological symptom was headache[27,28]. Claudio et al. have reported 103 patients hospitalized with SARS-CoV-2 infection, and $91.3 \%$ cases indicated at least one neurological disorder. Besides, sleep disturbance was the most common symptom, followed by dysgeusia, headache, hyposmia, and depression[29]. In the study by Eric et al., the most frequent neurological signs included myalgia (228; $44.8 \%)$, headache $(192 ; 37.7 \%)$, encephalopathy $(162 ; 31.8 \%)$, dizziness $(151 ; 29.7 \%)$, dysgeusia (81; $15.9 \%$ ), and anosmia (58; $11.4 \%$ )[30]. In the study of David et al. on 576 patients with COVID-19, 130 (22.6\%) patients complained of headache[31]. Following our study, similar surveys conducted on the frequency of neurological disorders associated with COVID-19 were acute ischemic stroke[32], GBS[33,34] , intracranial hemorrhage[35], encephalitis[36,37], multiple sclerosis[38], and altered consciousness[39].

The present study reported the prevalence of CNS disorders among age groups and found that the neurological symptoms are uncommon in patients below 30 years of age, but higher in cases over 60 years. Moreover, 54 patients were male. Similar studies have reported different results. For instance, Wu et al., according to a recent report by the China Centers for Disease Control and Prevention, reported a total of 965 infected patients under the age of 19 nationwide[40]. Carlos et al. displayed that the majority of patients had a mean age of 66.4 years, and $56.2 \%$ of cases were male[41], which supports our study. In Moran et al. survey, $53.6 \%$ of patients was male, and their median age was 42 years old[42]. In this regard, different studies have reported varied mean age in relation to neurological symptoms, e.g. ischemic stroke, Encephalitis[43], and intracranial hemorrhage (with 65.6, 45, and 38 years of age, respectively)[44]. In our study, the mortality rate of patients with and without neurological symptoms were $30.4 \%$ and $19.62 \%$, respectively. In a research work on 814 patients admitted to the hospital with confirmed SARS-CoV-2 infection, 329 (39.1\%) had severe neurologic complications, of which $4.1 \%$ died[23]. In another work, there were 48 (27.6\%) deaths, of which 22 were attributed to COVID-19 and 26 to stroke[45].indicating that the effect of the virus on the brain is greater and needs further investigation. A limitation of our study was mainly the small number of patients studied. Due to the prevalence of coronavirus, we were unable to have a direct communication with infected patients and reviewed only the records of hospitalized patients. Furthermore, some diagnostic methods, such as lumbar puncture and CSF examination, were performed to prevent the transmission of disease. For future studies, we propose more examples of patients with neurological symptoms in different populations. Moreover, we recommend the investigation of genetic differences and the role of the genome in response of patients to 
COVID-19. More research is required to investigate whether neurological symptoms occur as a direct effect of the virus on the brain or on other organs.

\section{Conclusion}

SARS-CoV-2 may involve nervous system and cause brain tissue damage. The results of this study assist neurologists in better understanding the occurrence, progression, and prognosis of neurological symptoms associated with COVID-19 disease. Our research work also helps other health care providers more precisely assess coronavirus disease and its symptoms for effective interventions to control the disease.

\section{Declarations}

\section{Ethics approval and consent to participate}

The study was approved by the Ethics Board of Hamedan University of Medical sciences.

\section{Consent for publication}

Written and informed consent was obtained from the patients.

\section{Availability of data and materials}

The data that support the findings of study are available from the corresponding author in Spss from upon reasonable request.

\section{Authors' contributions}

MK and FF developed the original idea and the protocol, abstracted and the manuscript and contributed to study design and data gathering . S k participated in the study design and analyzed the data. All authers read and approved the final manuscript.

\section{Acknowledgement}

We would like gratefully acknowledge all the staffs at Shahid Beheshti Hospital (Hamadan, Iran) who were involved in treating COVID-19 patients.

\section{Funding}

This work was supported by Hamedan University of Medical Sciences, Hamedan, Iran

\section{Competing interests}

All authors declare that they have no conflict of interest 


\section{References}

1. World Health Organization. Clinical management of severe acute respiratory infection when Novel coronavirus ( $\mathrm{nCoV}$ ) infection is suspected: interim guidance. January 2020. Accessed February 5,2020

2. Su S,Wong G, ShiW, et al. Epidemiology, geneticrecombination, and pathogenesis of coronaviruses. Trends Microbiol. 2016;24(6):490-502. doi:10.1016/j.tim.2016.03.003

3. Worldometer. COVID-19 Coronavirus Pandemic 2020 [updated August 01, 2020. Available from: https://www.worldometers.info/coronavirus

4. Giacomelli A, Pezzati L, Conti F, Bernacchia D, Siano M, Oreni L, et al. Self-reported olfactory and taste disorders in patients with severe acute respiratory coronavirus 2 infection: a cross-sectional study. Clinical Infectious Diseases. 2020;71(15):889-90.

5. Sun D, Li H, Lu X-X, Xiao H, Ren J, Zhang F-R, et al. Clinical features of severe pediatric patients with coronavirus disease 2019 in Wuhan: a single center's observational study. World Journal of Pediatrics. 2020:1-9.

6. Mao L, Jin H, Wang M, Hu Y, Chen S, He Q, et al. Neurologic manifestations of hospitalized patients with coronavirus disease 2019 in Wuhan, China. JAMA neurology. 2020;77(6):683-90.

7. Montalvan V, Lee J, Bueso T, De Toledo J, Rivas K. Neurological manifestations of COVID-19 and other coronavirus infections: a systematic review. Clinical Neurology and Neurosurgery. 2020;194:105921.

8. Moriguchi T, Harii N, Goto J, Harada D, Sugawara H, Takamino J, et al. A first case of meningitis/encephalitis associated with SARS-Coronavirus-2. International Journal of Infectious Diseases. 2020;94:55-8.

9. Poyiadji N, Shahin G, Noujaim D, Stone M, Patel S, Griffith B. COVID-19-associated acute hemorrhagic necrotizing encephalopathy: imaging features. Radiology. 2020;296(2):E119-E20.

10. Mao L, Jin H, Wang M, Hu Y, Chen S, He Q, Chang J, Hong C, Zhou Y, Wang D, Miao X, Li Y, Hu B. Neurologic manifestations of hospitalized patients with coronavirus disease 2019 in Wuhan, China. JAMA Neurol 2020.

11. GuanWJ, Ni ZY, Hu Y, et al; China Medical Treatment Expert Group for Covid-19. Clinical characteristics of coronavirus disease 2019 in China. N Engl J Med. 2020.doi:10.1056/NEJMoa2002032

12. Ebers GC. Environmental factors and multiple sclerosis.Lancet Neurol. (2008) 7:268-77. 10.1016/S1474-4422(08)70042-5

13. Olsson T, Barcellos LF, Alfredsson L. Interactions between genetic, lifestyle and environmental risk factors for multiple sclerosis. Nat Rev Neurol. (2017) 13:25. 10.1038/nrneurol.2016.187

14. Morfopoulou S, Brown JR, Davies EG, Anderson G, Virasami A, Qasim W, et al. . Human coronavirus OC43 associated with fatal encephalitis. N Engl J Med. (2016) 375:497-8. 10.1056/NEJMc1509458 Guillain-Barre syndrome during COVID-19 pandemic: an overview of the reports 
15. Rahimi K. Guillain-Barre syndrome during COVID-19 pandemic: an overview of the reports. Neurological Sciences. 2020 Sep 2:1-8

16. Lechien JR, Chiesa-Estomba CM, De Siati DR, Horoi M, Le Bon SD, Rodriguez A, et al. Olfactory and gustatory dysfunctions as a clinical presentation of mild-to-moderate forms of the coronavirus disease (COVID-19): A multicenter European study. Eur Arch Otorhinolaryngol 2020:1-11. doi: 10.1007/s00405-020-05965-1

17. Bolton CFGilbertJJHahnAFSibbald WJ Polyneuropathy in critically ill patients. J NeurolNeurosurg Psychiatry. 1984;471223- 1231

18. Bolton CFYoungGBZochodne DW The neurological complications of sepsis. Ann Neurol. 1993;3394100

19. SherJHShafiqSASchutta HS Acute myopathy with selective lysis of myosin filaments. Neurology. 1979;29100- 106

20. Mao L, Jin H, Wang M, et al. Neurologic manifestations of hospitalized patients with coronavirus disease 2019 in Wuhan, China. JAMA Neurol 2020;77:683-690.

21. Romero-Sánchez CM, Díaz-Maroto I, Fernández-Díaz E, et al. Neurologic manifestations in hospitalized patients with COVID-19: the ALBACOVID registry. Neurology 2020;95:e1060-e1070.

22. Metlay JP, Waterer GW, Long AC, et al. . Diagnosis and treatment of adults with community-acquired pneumonia: an official clinical practice guideline of the American Thoracic Society and Infectious Disease Society of America. Am J RespirCrit Care Med. 2019;200(7):e45-e67. doi:10.1164/rccm.201908-1581.

23. Mahammedi A., Saba L., Vagal A. Imaging in Neurological Disease of Hospitalized COVID-19 Patients: an Italian Multicenter Retrospective Observational Study. Radiology. 2020;297S(2) doi: 10.1148/radiol.2020201933. E270-E273.

24. Guilmot A., Maldonado Slootjes S., Sellimi A. Immune-mediated neurological syndromes in SARSCoV-2-infected patients. J Neurol. 2020:1-7. doi: 10.1007/s00415-020-10108-x.

25. Romero-Sánchez C.M., Díaz-Maroto I., Fernández-Díaz E. Neurologic manifestations in hospitalized patients with COVID-19: the ALBACOVID registry. Neurology. 2020;95(8) doi:

10.1212/WNL.0000000000009937. e1060-e1070 [Published online June 1, 2020:10.1212/WNL. 0000000000009937]

26. Li Y, Wang M, Zhou Y, Chang J, Xian Y, Mao L, et al. Acute Cerebrovascular Disease Following COVID19: A Single Center. Retrospective, Observational Study. 2020 https://doi.org/10.2139/ssrn.3550025.

27. Ömer k, Bilgin Ö , Ali Rıza S , A prospective clinical study of detailed neurological manifestations in patients with COVID-19. Neurological Sciences $2020: 41-1995$

28. Imen K, Alya G, Chahida H et al. Characteristics, onset, and evolution of neurological symptoms in patients with COVID-19. Neurological Sciences 2021 . 42: 39-46

29. Claudio I, Mariangela $p$, Matteo S. Subjective neurological symptoms frequently occur in patients with SARS-CoV2 infection. 2020, 88: 11-16 https://doi.org/10.1016/j.bbi.2020.05.037 
30. Eric M, Liotta A, Jeffrey R et al , Frequent neurologic manifestations and encephalopathy-associated morbidity in Covid-19 patients. October 2020.7: 11- 2221-2230

31. 32David G, Javier T, Blanca T et al . Frequency and Type of Red Flags in Patients With Covid-19 and Headache: A Series of 104 Hospitalized Patients. American Headache Society doi: 10.1111/head.13927 2020;60(8):1664-1672

32. Oxley TJ, Mocco J, Majidi S, Kellner CP, Shoirah H, Singh IP, et al. Large-vessel stroke as a presenting feature of COVID-19 in the young. N Engl J Med. 2020;382(20):e60. . https://doi.org/10.1056/nejmc2009787.

33. Zhao H, Shen D, Zhou H, Liu J, Chen S. Guillain-barré syndrome associated with SARS-CoV-2 infection: Causality or coincidence? Lancet Neurol. 2020;19(5):383-4. \%https://doi.org/10.1016/s1474-4422(20)30109-5.

34. Toscano G, Palmerini F, Ravaglia S, Ruiz L, Invernizzi P, Cuzzoni MG, et al. Guillain-barré syndrome associated with SARS-CoV-2. N Engl J Med. 2020:NEJMc2009191. .https://doi.org/10.1056/nejmc2009191.

35. Sharifi-Razavi A, Karimi N, Rouhani N. COVID 19 and intra cerebral hemorrhage: Causative or coincidental. New Microbes New Infect. 2020;35:100669. https://doi.org/10.1016/j.nmni.2020.100669.

36. Xinhua. Beijing Hospital Confirms Nervous System Infections by Novel Coronavirus. Beijing: Xinhua; 2020. [[Last accessed on 2020 Mar 05]]. Available from: -/http://www.china.org.cn/china/202003/05/content_75777888.htm .

37. Moriguchi T, Harii N, Goto J, Harada D, Sugawara H, Takamino J, et al. A first Case of meningitis/encephalitis associated with SARS-Coronavirus-2. Int J Infect Dis. 2020;94:55-8.

38. Boucher A, Desforges $M$, Duquette $P$, Talbot PJ. Long-term human coronavirus-myelin cross-reactive T-cell clones derived from multiple sclerosis patients. Clinlmmunol. 2007;123(3):258-67. .https://doi.org/10.1016/j.clim.2007.02.002.

39. Yin R, Feng W, Wang T, et al. Concomitant neurological symptoms observed in a patient diagnosed with coronavirus disease 2019. J Med Virol. 2020

40. Wu Z, McGoogan JM. Characteristics of and important lessons from the coronavirus disease 2019 (COVID-19) outbreak in China: summary of a report of 72,314 cases from the Chinese Center for Disease Control and Prevention. JAMA. 2020 . ..https://doi.org/10.1001/jama.2020.2648.

41. Carlos $m$, Inmaculada d, Eva f Neurologic manifestations in hospitalized patients with COVID-19. 2020; 95 (8) dOI: https://doi.org/10.1212/WNL.0000000000009937

42. Moran K, Epidemiologic characteristics of early cases with 2019 novel coronavirus (2019-nCoV) disease in Korea. Epidemiol Health. 2020;42:e2020007. doi: 10.4178/epih.e2020007

43. Arabi Y.M., Harthi A., Hussein J., Bouchama A., Johani S., Hajeer A.H. Severe neurologic syndrome associated with Middle East respiratory syndrome coronavirus (MERS-CoV) Infection. 2015;43:495501. 
44. Algahtani H., Subahi A., Shirah B. Neurological Complications of Middle East Respiratory Syndrome Coronavirus: A Report of Two Cases and Review of the Literature. Case Rep Neurol Med. 2016;2016 45. George N, Patrik M, Georgios G. Characteristics and Outcomes in Patients With COVID-19 and Acute Ischemic Stroke. 2020 Jul 13: 10.1161/STROKEAHA.120.031208. doi:

10.1161/STROKEAHA.120.031208

\section{Tables}

Table 1. Demographic characteristics of COVID-19 patients based on their CNS involvement 


\begin{tabular}{|c|c|c|c|c|}
\hline Variables & $\begin{array}{l}\text { Patients with CNS } \\
\text { symptoms (\%) }\end{array}$ & $\begin{array}{l}\text { Patients without CNS } \\
\text { symptoms (\%) }\end{array}$ & $\begin{array}{l}P \\
\text { value }\end{array}$ & $\begin{array}{l}\text { Total } \\
\text { cases }(\%)\end{array}$ \\
\hline \multicolumn{5}{|l|}{ Gender } \\
\hline Male & $54(51.43)$ & $197(52.96)$ & \multirow[t]{2}{*}{0.78} & $\begin{array}{l}251 \\
(52.62)\end{array}$ \\
\hline Female & $51(48.57)$ & $175(47.04)$ & & $\begin{array}{l}226 \\
(47.38)\end{array}$ \\
\hline \multicolumn{5}{|l|}{ Age group (year) } \\
\hline$<30$ & $4(3.81)$ & $8(2.12)$ & \multirow[t]{4}{*}{0.18} & $12(2.52)$ \\
\hline $30-45$ & 19 (18.10) & $62(16.7)$ & & $\begin{array}{l}81 \\
(16.98)\end{array}$ \\
\hline $46-60$ & 16 (15.24) & $92(24.73)$ & & $\begin{array}{l}108 \\
(22.64)\end{array}$ \\
\hline $60+$ & $66(62.86)$ & $210(56.45)$ & & $\begin{array}{l}276 \\
(57.86)\end{array}$ \\
\hline \multicolumn{5}{|l|}{ Marital status } \\
\hline Single & $4(3.81)$ & $12(3.33)$ & \multirow[t]{2}{*}{0.77} & $16(3.35)$ \\
\hline Married & $101(96.19)$ & $360(96.77)$ & & $\begin{array}{l}461 \\
(96.65)\end{array}$ \\
\hline \multicolumn{5}{|l|}{ Smoking } \\
\hline Yes & $23(21.90)$ & 31 (8.33) & \multirow[t]{2}{*}{$<0.001$} & $\begin{array}{l}54 \\
(11.32)\end{array}$ \\
\hline No & 82(78.10) & 341 (91.67) & & $\begin{array}{l}423 \\
(88.68)\end{array}$ \\
\hline \multicolumn{5}{|l|}{$\begin{array}{l}\text { Underlying } \\
\text { disease }\end{array}$} \\
\hline HTN & 32 (30.47) & 135 (36.29) & \multirow[t]{3}{*}{0.66} & $\begin{array}{l}184 \\
(38.57)\end{array}$ \\
\hline $\begin{array}{l}\text { Cardiovascular } \\
\text { disease }\end{array}$ & 17 (16.19) & 67 (18.01) & & $\begin{array}{l}96 \\
(20.12)\end{array}$ \\
\hline Diabetes & $24(22.86)$ & 90 (24.19) & & $\begin{array}{l}136 \\
(28.51)\end{array}$ \\
\hline
\end{tabular}




\section{Disease outcome}

\begin{tabular}{|c|c|c|c|c|}
\hline Death & $32(30.47)$ & 73 (19.62) & 0.012 & $\begin{array}{l}105 \\
(22.01)\end{array}$ \\
\hline Remission & 73 (69.52) & 299 (80.37) & & $\begin{array}{l}372 \\
(77.99)\end{array}$ \\
\hline Total & 105 (22.02) & 372 (78.98) & & 477 \\
\hline
\end{tabular}

Table 2. The occurrence of neurological symptoms based on the patients' gender

\begin{tabular}{|c|c|c|c|c|}
\hline \multirow[t]{3}{*}{ Neurologic symptoms } & \multirow[t]{3}{*}{ Total (\%) } & \multicolumn{2}{|l|}{ Gend'er } & \multirow[t]{3}{*}{$P$ value } \\
\hline & & Males (\%) & Females (\%) & \\
\hline & & $(n=251)$ & $(n=226)$ & \\
\hline Headache & $13(2.72)$ & $6(2.39)$ & $7(3.1)$ & 0.68 \\
\hline Encephalitis & $5(1.05)$ & $1(0.4)$ & $4(1.77)$ & 0.19 \\
\hline Ischemic stroke & $34(7.13)$ & $15(5.98)$ & $19(8.41)$ & 0.37 \\
\hline Convulsions & $11(2.31)$ & $7(2.8)$ & $4(1.77)$ & 0.55 \\
\hline Cerebral hemorrhage & $6(1.26)$ & $4(1.59)$ & $2(0.88)$ & 0.69 \\
\hline Venous thrombosis & $3(0.63)$ & 0 & $3(1.33)$ & 0.11 \\
\hline Decreased consciousness & $28(5.88)$ & $15(5.98)$ & $13(5.75)$ & 1 \\
\hline Guillain-Barre syndrome & $2(0.42)$ & $2(0.8)$ & 0 & 0.5 \\
\hline Hyposmia & $6(1.26)$ & $2(0.8)$ & $4(1.77)$ & 0.43 \\
\hline Other neuropathies & $17(3.56)$ & $10(3.98)$ & $7(3.10)$ & 0.63 \\
\hline
\end{tabular}

Table 3. The occurrence of neurologic symptoms based on the patients' age group 


\begin{tabular}{|c|c|c|c|c|}
\hline \multirow[t]{3}{*}{ Neurological symptoms } & \multicolumn{4}{|c|}{ Age group (year) } \\
\hline & $<30(\%)$ & $30-45(\%)$ & $46-60(\%)$ & $+60(\%)$ \\
\hline & $(n=12)$ & $(n=81)$ & $(n=108)$ & $(n=276)$ \\
\hline Headache & $1(8.33)$ & $5(6.15)$ & $2(1.85)$ & $5(1.81)$ \\
\hline Encephalitis & 0 & 0 & $2(1.85)$ & $3(1.09)$ \\
\hline Ischemic stroke & $1(8.33)$ & $1(1.23)$ & $2(1.85)$ & $30(10.87)$ \\
\hline Convulsions & $1(8.33)$ & $3(3.69)$ & 0 & $7(2.54)$ \\
\hline Cerebral hemorrhage & 0 & $1(1.23)$ & $2(1.85)$ & $3(1.09)$ \\
\hline Venous thrombosis & 0 & 0 & $1(0.93)$ & $2(0.72)$ \\
\hline Decreased consciousness & 0 & $2(2.46)$ & $3(2.78)$ & $23(8.33)$ \\
\hline Guillain-Barre syndrom & 0 & $1(1.23)$ & $1(0.93)$ & 0 \\
\hline Hyposmia & $1(8.33)$ & $1(1.23)$ & $4(3.7)$ & 0 \\
\hline Other neuropathies & $1(8.33)$ & $5(6.15)$ & $4(3.7)$ & $7(2.54)$ \\
\hline
\end{tabular}

Table 4. Laboratory Findings of patients with neurological manifestation

\begin{tabular}{|llllll|}
\hline Biomarker & Median (IQR) & $\begin{array}{l}\text { Standard } \\
\text { range }\end{array}$ & $\begin{array}{l}\text { Lower than } \\
\text { standard } \\
\text { range }\end{array}$ & $\begin{array}{l}\text { In } \\
\text { range }\end{array}$ & $\begin{array}{l}\text { Higher than standard } \\
\text { range }\end{array}$ \\
\hline WBC & $7700(5900,10900)$ & $4000-10000$ & 27 & 60 & 11 \\
\hline Palates & $\begin{array}{l}188000(152000, \\
247000)\end{array}$ & $\begin{array}{l}150000- \\
450000\end{array}$ & 3 & 73 & 24 \\
\hline Neutrophil & $75(65,85)$ & $55-73$ & 53 & 13 & 30 \\
\hline Lymphocyte & $16(10,23)$ & $20-40$ & 1 & 56 & 39 \\
\hline
\end{tabular}

\section{Figures}



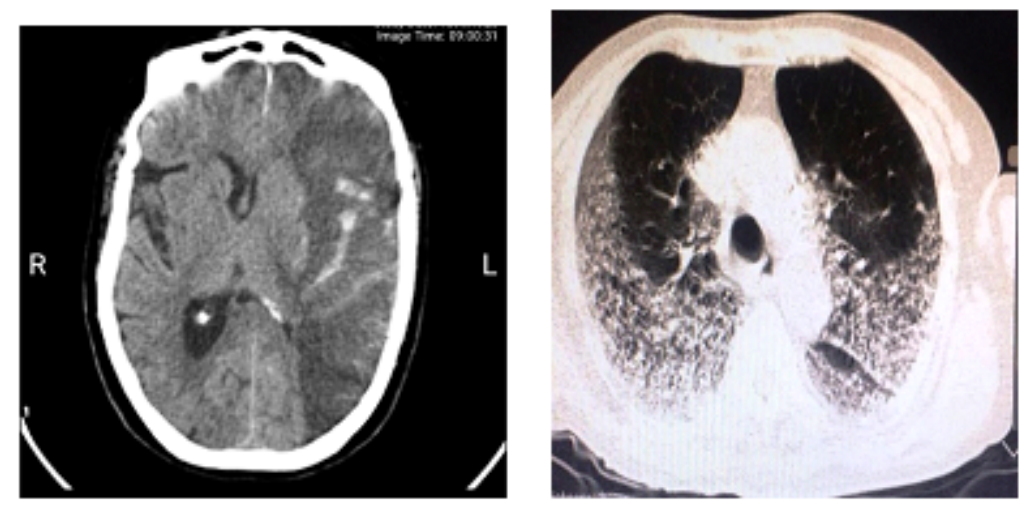

Figure 1

CT images of a COVID-19 patient with acute symptoms of ischemic stroke
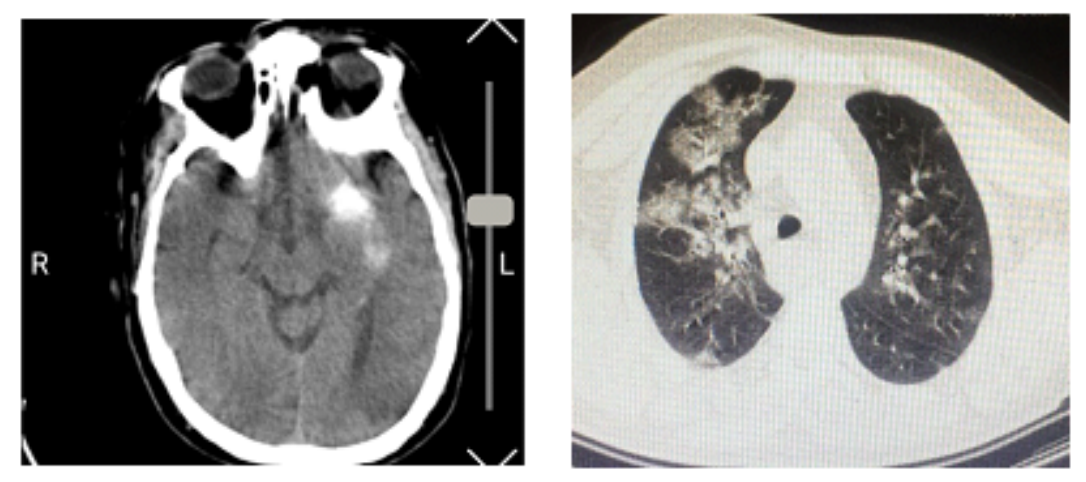

Figure 2

CT images of a COVID-19 patient with acute symptoms of ischemic stroke 